\title{
Posttraumatic stress disorder: prevalences, comorbidities and quality of life in a community sample of young adults
}

Transtorno de estresse pós-traumático: prevalências, comorbidades e qualidade de vida em uma amostra comunitária de adultos jovens

Letícia Galery Medeiros', Ricardo Azevedo da Silva', Luciano Dias de Mattos Souza', Giovanna Del Grande da Silva', Ricardo Tavares Pinheiro', Karen Jansen¹

\section{Keywords}

Posttraumatic stress disorder, depression, quality of life, young adults.

\section{Palavras-chave}

Transtorno de estresse pós-traumático, depressão, qualidade de vida, adultos jovens.

\begin{abstract}
Objectives: To verify the prevalence of current posttraumatic stress disorder (PTSD) in young adults, the occurrence of comorbidities and its association with quality of life. Methods: This is a cross-sectional population-based study. The targeted population consisted on individuals aged 18 to 24 years old, who lived in the urban area of Pelotas-RS, Brazil. Cluster sampling was applied. PTSD and its comorbidities were assessed using the Mini International Neuropsychiatric Interview (MINI 5.0), whereas quality of life was evaluated with the eight domains of the Medical Outcomes Survey Short-form General Health Survey (SF-36). Results: A total of 1,762 young adults were selected. The prevalence of PTSD was $2.1 \%$ and current episode of depression was the most prevalent comorbidity (71.9\%). The individuals with PTSD had lower scores in all domains of quality of life. Conclusion: These findings indicate that PTSD is associated with other psychopathologies, especially depression, and it has a substantial impact over quality of life in a sample of young adults.
\end{abstract}

\section{RESUMO}

Objetivos: Verificar a prevalência de transtorno de estresse pós-traumático (TEPT) atual em adultos jovens, a ocorrência de comorbidades e sua associação com a qualidade de vida. Métodos: Estudo transversal de base populacional, tendo como população-alvo indivíduos de 18 a 24 anos de idade, residentes na zona urbana do município de Pelotas-RS, Brasil. A seleção amostral foi realizada por conglomerados, com um pulo de três domicílios entre os selecionados. O TEPT e as comorbidades foram avaliados pela Mini International Neuropsychiatric Interview (MINI 5.0), enquanto a qualidade de vida foi mensurada por oito domínios da SF-36. Resultados: No total, 1.762 jovens foram selecionados. A prevalência de TEPT foi de 2,1\%; entre esses, a depressão foi o transtorno mais ocorrente (71,9\%). Em todos os domínios da qualidade de vida, os jovens com TEPT obtiveram escores mais baixos. Conclusão: Os achados indicam que o TEPT se encontra associado a outras psicopatologias, principalmente a depressão, e apresenta substancial impacto na qualidade de vida em uma amostra de jovens.

1 Universidade Católica de Pelotas (UCPel), Programa de Pós-Graduação em Saúde e Comportamento.

Address for correspondence: Karen Jansen Rua Gonçalves Chaves, 412, sala 416C, Centro 96010-000 - Pelotas, RS, Brazil Telephones: +55 (53) 2128-8404/(53) 8118-6112 E-mail: jansen@ucpel.tche.br 


\section{INTRODUCTION}

Posttraumatic stress disorder (PTSD) is the mental disorder that is most strongly associated to violence and disaster situations'. A portion of the people who have survived traumatic experiences will develop PTSD symptoms: re-experience of the trauma (intrusive thoughts, flashbacks, nightmares), emotional avoidance/numbness (avoidance of memories of the traumatic event) and autonomic hyperstimulation (hypervigilance and sleep disorders) ${ }^{2}$.

Even though the diagnostic criteria for PTSD is so specific, its identification is complicated by the presence of comorbidities. The occurrence of comorbidities may cover its diagnosis and make it harder to identify the PTSD, since some of the symptoms are commonly presented in other disorders ${ }^{3}$. Moreover, it may be also difficult for people to voluntarily report their traumatic experiences. Therefore, it is recommended that clinicians investigate all suspect cases - the ones with greater probability of PTSD - which consist on patients with depressive and/or anxiety symptoms and/or with a history of substance use or abuse 4 .

The strong association between PTSD and other disorders, such as depression, generalized anxiety disorder, and the use of psychoactive substances, significantly increases the impairments inherent to the disorder. This impairment usually interfere with the perception of quality of life, especially regarding the quality of relationships and occupational abilities, which leads to a negative impact on the individual's general functioning ${ }^{5}$.

Studies suggest that young adults between 18 and 24 years of age, such as the targeted population in this study, are at high risk for developing PTSD $^{6,7}$. Adolescence is considered to be a transition phase between childhood and adulthood; it is characterized by multiple physical and psychic changes that would be responsible for typical conflict and behavior. It is also identified as a critical period for the development of mental disorders ${ }^{6}$.

Finally, in Brazil, there is little evidence about the prevalence of PTSD. The most of estimates are originated from local data from medical and/or mental health services at primary care or hospitals or specific violent situations. Thus, this study aims to present the prevalence of current PTSD among young adults aged 18 to 24 years old, domiciled in the urban area of Pelotas, RS (Brazil), as well as to verify the association of PTSD with socio-demographic characteristics, the occurrence of comorbidities and the possible impact on quality of life.

\section{METHODS}

This is a cross-sectional population-based study with young adults aged 18-24 year-old, who lived in the urban area of Pelotas, RS (Brazil). The sample selection was performed by clusters considering the population of 39,667 in the age range according to the current census of 448 sectors in the city (Instituto Brasileiro de Geografia e Estatística - IBGE, 2007) ${ }^{8}$, from which 89 sectors were randomly selected. Homes were selected within the sectors using a systematic sampling; the first house being the one at the corner designated by the IBGE as the beginning of the sector; every third house was selected. Data collection was conducted between 2009 and 2010. For more information regarding sampling process, see Jansen et al. ${ }^{9}$.

After identifying the subjects, well-trained interviewers from the Universidade Católica de Pelotas (UCPel) explained the purposes of the study. The subjects who agreed to participate provided signed informed consent and answered a questionnaire regarding socio-demographic data, use of psychoactive substances, quality of life, and they also participated in a structured interview for the identification of axis I disorders in the DSM-IV. The exclusion criteria were inability to respond to the questionnaire and/or cognitive impairments.

The socio-demographic questionnaire contained questions concerning age, gender, marital status (living with a partner) and occupation. Socio-economic evaluation was performed through the classification from the Associação Brasileira de Empresas de Pesquisa (Abep, 2012) ${ }^{10}$, which is based on the total of material goods and in the householder's schooling. This classification categorizes people into the socio-economic classes A, B, C, D or E, where "A" refers to the highest socio-economic class and " $E$ " to the lowest one.

Information concerning the use of psychoactive substances was obtained using the Alcohol, Smoking and Substance Involvement Screening Test (ASSIST 2.0/OMS) ${ }^{11}$, which has been adapted and validated for Brazilian use. It is a structured questionnaire containing eight questions about the use of nine classes of psychoactive substances (tobacco, alcohol, marijuana, cocaine, stimulants, sedatives, inhalants, hallucinogens, and opiates). The questions address the frequency of use, in life and in the past three months, problems related to using, concern regarding use by people close to the user, prejudice in the execution of tasks expected, unsuccessful attempts to stop or reduce use, feelings of compulsion and use via injection. Each response corresponds to a score, which ranges from 0 to 4, with the sum total can vary from 0 to 20. It is considered the score range 0 to 3 as indicative of occasional use, from 4 to 15 as indicative of abuse and $\geq 16$ as suggestive of dependency. Internal consistence of the instrument was considered good, with sensibility levels ranging from $84 \%$ to $91 \%$, specificity from $79 \%$ to $98 \%$, positive prediction values of $80 \%$ to $93 \%$, and negative prediction values of $85 \%$ to $96 \%$. Crack was also included in the list of drugs investigated by the ASSIST.

The levels of quality of life were obtained through the Medical Outcomes Survey Short-form General Health Survey (SF-36) ${ }^{12}$ which consists on 36 items regarding daily life limitations due to health issues. This survey provides a subjective estimation of the individual's general condition in eight do- 
mains: role physical health, physical functioning, bodily pain, vitality, social functioning, role emotional, mental health and general health. The scores range from 0 to 100, with higher values representing better quality of life. The SF-36 is suitable for self-administration, computerized administration, or administration by a trained interviewer in person or by telephone, to persons age 14 and older. Reliability coefficients for the eight domains ranged from 0.77 to 0.94 with a mean value of 0.82 , validity values ranged from 0.51 to 0.85 . More information about psychometric properties was found in $\mathrm{Ci}$ conelli et al. ${ }^{12}$.

Current PTSD and comorbidities evaluation was carried out using the Mini International Neuropsychiatric Interview $5.0(\mathrm{MINI})^{13}$. This short interview (15-30 minutes) is designed to be used at clinical practice and for research purposes, aiming to evaluate the individuals according to the DSM-IV. Clinicians learn how to use it after a short training (1-3 hours). The priority is the exploitation of current disorders. The quotation of the issues is dichotomous (yes/no). For all diagnostic sections (except the psychotic disorders section), one or two input issues that exploit mandatory criteria allow you to exclude the diagnosis in case of negative responses. Dysfunction induced by movement disorders and the exclusion of somatic and/or toxic causes of symptoms are not systematically exploited. The algorithms are integrated into the structure of the questionnaire, allowing to establish or exclude diagnoses throughout the interview. The diagnostic independent modules considered for this study were currents episodes from: depression, suicide risk, panic disorder, agoraphobia, social phobia, obsessive compulsive disorder, posttraumatic stress disorder and generalized anxiety disorder.

The participants who presented any psychiatric disorders according to the MINI and/or drug abuse were referred to psychiatric outpatient care at UCPel. The project was approved by the Ethic Committee on Research of UCPel, according to the protocol 2006/96.

After the instruments were codified, they were double-typed into Epi-Info 6.04 with immediate checking of data entry and verification of the consistency of the two data input. Stata 9 (Data Analysis and Statistical Software, 2009) software was used for data analysis, with an initial aim of obtaining the prevalence of current PTSD and characterizing the sample. The chi-square test was used to describe the association between the occurrence of PTSD and the independent variables. The Linear Regression was applied to compare the mean scores of the eight domains of quality of life and the occurrence of PTSD.

The variables that presented a $p$-value $<0.20$ were included in a model of adjusted analysis. In order to verify which factors were associated with PTSD, a Poisson regression adjusted for gender, current study, marital status and socio-economic classification was carried out. Finally, associations with $p \leq 0.05$ were considered statistically significant.

\section{RESULTS}

A total of 1,762 young adults were identified, although 202 (11.5\%) refused to participate in the study or were not found at their homes. Thus, the final sample was composed of 1,560 young adults who were mostly women, with a mean age of 20 years old, who were currently studying, did not live with a partner, and who were categorized in the socioeconomic class C (Table 1).

The prevalence of current PTSD in this sample was 2.1\%. The prevalence was higher amongst women, individuals who lived with a partner, who were currently working and the ones who belonged to lower socioeconomic classes ( $D$ and $E$ ). After the adjusted analysis, the variables gender and marital status remained associated with the occurrence of PTSD (Table 1).

Although current PTSD was significantly associated to all anxiety disorders, it was strongly associated with current depressive episode; suicide risk was identified in $53.1 \%$ of these individuals. Concerning substance abuse and/or dependence, tobacco ( $p=0.001)$ and illicit substances $(p<0.001)$ were significantly associated with the occurrence of current PTSD (Table 2).

The young adults who were diagnosed with current PTSD presented lower scores in all eight domains of quality of life, when compared to the general population from the study, even after adjusting for possible confounding factors (Table 3 ).

\section{DISCUSSION}

This investigation demonstrated that the prevalence of current PTSD in young adults is in accordance with the parameters estimated in literature ${ }^{14,15}$. The prevalence of PTSD was higher amongst women and individuals who lived with a partner. Regarding comorbidities, there was a strong association between PTSD and current depressive episode, and between PTSD and the use of psychoactive substances. Moreover, the group presenting current PTSD revealed Iower quality of life scores when compared to the individuals without the disorder.

Data from the National Comorbidity Survey Replication ${ }^{16}$ point to the age of 14 years as a critical moment for the onset of some disorders, such as: panic disorder, generalized anxiety disorder, posttraumatic stress disorder, use/abuse of substances, and mood disorders. Studies on anxiety disorders demonstrate that it mostly begins between childhood and adolescence; and that they present a strong tendency of persisting throughout adulthood ${ }^{7}$. Regarding the PTSD, there is vast evidence about the existing relationship between physica $1{ }^{17}$ or sexual ${ }^{18}$ violence suffered in childhood and the onset of PTSD at subsequent ages ${ }^{18,19}$. Young individuals diagnosed with PTSD present greater severity of anxious and depressive symptoms, as well as a greater number comorbidity with other mental disorders, which increases clinical complexity ${ }^{20}$. 
Although mental health researches in Brazil prioritize mood and anxiety disorders, only a few local studies can be found using samples mostly from public health care ${ }^{21}$. An important multicentric population-based study evaluated the prevalence of mental disorders in 6,476 individuals over 15 years of age, in three Brazilian great urban centers (São Paulo, Porto Alegre and Brasília). Their results revealed that anxiety disorders were amongst the most prevalent disorders $(51 \%$ in Brasília, 43\% in Porto Alegre and 30\% in São
Paulo); however, information about the anxiety disorders are not presented separately ${ }^{22}$. Another population-based study conducted in the city of São Paulo showed a high prevalence of mental disorders in urban population, being PTSD prevalent in $1.6 \%$ of the sample, from whom $51 \%$ presented severe symptoms ${ }^{23}$. In western countries, the prevalence of PTSD ranges from $0.7 \%$ in France ${ }^{14}$ to $3.5 \%$ in the United States ${ }^{15}$. These data are similar to the ones found in the present work.

Table 1. Sociodemographic sample characteristics and its relation to the presence of current posttraumatic stress disorder

\begin{tabular}{|c|c|c|c|c|c|c|}
\hline \multirow{2}{*}{ Variables } & \multirow{2}{*}{ Sample distribution } & \multirow{2}{*}{$\begin{array}{c}\text { Current prevalence } \\
\text { of PTSD }\end{array}$} & \multicolumn{2}{|c|}{ Crude analysis } & \multicolumn{2}{|c|}{ Adjusted analysis } \\
\hline & & & PR (C195\%) & $p$ & $\operatorname{PR}(C \mid 95 \%)$ & $p$ \\
\hline Gender & & & & 0.020 & & 0.027 \\
\hline Feminine & $56.4 \%(880)$ & $2.8 \%(25)$ & $2.76(1.20-6.34)$ & & $2.56(1.11-5.87)$ & \\
\hline Male & $43.6 \%(680)$ & $1.0 \%(07)$ & 1.00 & & 1.00 & \\
\hline Age & & & & 0.289 & & \\
\hline $18-20$ years & $51.0 \%(795)$ & $1.6 \%(13)$ & 1.00 & & & \\
\hline 21-24 years & $48.3 \%(753)$ & $2.4 \%(18)$ & $1.50(0.72-2.96)$ & & & \\
\hline Marital status & & & & 0.001 & & 0.039 \\
\hline Single & $71.9 \%(1121)$ & $1.3 \%(15)$ & 1.00 & & 1.00 & \\
\hline Married & $28.1 \%(439)$ & $3.9 \%(17)$ & $2.89(1.46-5.74)$ & & $2.05(1.03-4.08)$ & \\
\hline Current study & & & & 0.062 & & 0.348 \\
\hline No & $54.0 \%(843)$ & $2.7 \%(23)$ & $2.37(1.01-4.67)$ & & $1.43(0.68-3.01)$ & \\
\hline Yes & $46.0 \%(717)$ & $1.3 \%(09)$ & 1.00 & & 1.00 & \\
\hline Current work ${ }^{\mathbf{a}}$ & & & & 0.817 & & \\
\hline No & $40.4 \%(387)$ & $3.1 \%(12)$ & 1.00 & & & \\
\hline Yes & $59.6 \%(570)$ & $2.6 \%(15)$ & $1.18(0.56-2.49)$ & & & \\
\hline Socioeconomic classification & & & & 0.009 & & 0.065 \\
\hline$A+B$ & $37.4 \%(583)$ & $1.4 \%(08)$ & 1.00 & & 1.00 & \\
\hline$c$ & $48.1 \%(751)$ & $1.6 \%(12)$ & $1.16(0.48-2.83)$ & & $0.81(0.35-1.86)$ & \\
\hline $\mathrm{D}+\mathrm{E}$ & $14.5 \%(226)$ & $5.3 \%(12)$ & $3.87(1.60-9.34)$ & & $2.49(1.04-5.97)$ & \\
\hline Total & 1560 & $2.1 \%(32)$ & & & & \\
\hline
\end{tabular}

Notes: PR: prevalence rate; Cl: confidence interval.

The variable contains missing value.

Table 2. Distribution of current anxiety disorders, depression, suicide risk, alcohol, tobacco and other substances abuse; and their association with the presence of current PTSD

\begin{tabular}{|c|c|c|c|c|}
\hline Mental disorders & $\begin{array}{c}\text { Sample distribution } \\
\%(\boldsymbol{n})\end{array}$ & Prevalence of PTSD & $\mathrm{PR}^{\mathrm{a}}$ (C) 95\%) & $p$ value \\
\hline Panic disorder & $12.3 \%(192)$ & $10.3 \%(04)$ & $37.45(26.32-53.28)$ & $<0.000$ \\
\hline Social phobia & $4.0 \%(63)$ & $17.5 \%(11)$ & $9.16(4.63-18.12)$ & $<0.000$ \\
\hline Obsessive-compulsive disorder & $3.0 \%(51)$ & $21.6 \%(11)$ & $15.50(7.9-30.41)$ & $<0.000$ \\
\hline Agoraphobia & $12.3 \%(192)$ & $9.4 \%(18)$ & $9.16(4.63-18.12)$ & $<0.000$ \\
\hline Generalized anxiety disorder & $9.7 \%(152)$ & $9.9 \%(15)$ & $8.17(4.17-16.03)$ & $<0.000$ \\
\hline Depression & $12.6 \%(196)$ & $71.9 \%(23)$ & $17.78(8.35-37.87)$ & $<0.000$ \\
\hline Suicide risk & $8.6 \%(134)$ & $53.1 \%(17)$ & $12.06(6.16-23.6)$ & $<0.000$ \\
\hline Alcohol abuse/dependence & $24.9 \%(389)$ & $2.6 \%(11)$ & $1.43(0.69-2.93)$ & 0.332 \\
\hline Tobacco abuse/dependence & $24.9 \%(389)$ & $4.1 \%(16)$ & $3.01(1.52-5.96)$ & 0.001 \\
\hline Other substances abuse/dependence & $7.4 \%(116)$ & $8.6 \%(10)$ & $5.66(2.75-11.66)$ & $<0.001$ \\
\hline
\end{tabular}

Note: PR: prevalence rate. The prevalence rate was calculated using the absence of the disorder as reference. 
Table 3. Linear regression between posttraumatic stress disorder and the scores on the eight SF-36 subscales, adjusted for gender, socio-economic situation, studying and relationship status

\begin{tabular}{lcc}
\hline Quality of life & Regression coefficient & $\boldsymbol{p}$ value \\
\hline Role physical health & -10.353 & $<0.001$ \\
Physical functioning & -44.386 & $<0.001$ \\
General health & -23.300 & $<0.001$ \\
Vitality & -23.258 & $<0.001$ \\
Role emotional & -46.996 & $<0.001$ \\
Mental health & -35.232 & $<0.001$ \\
Social functioning & -35.700 & $<0.001$ \\
Bodily pain & -22.311 & $<0.001$ \\
\hline
\end{tabular}

Individuals with current PTSD

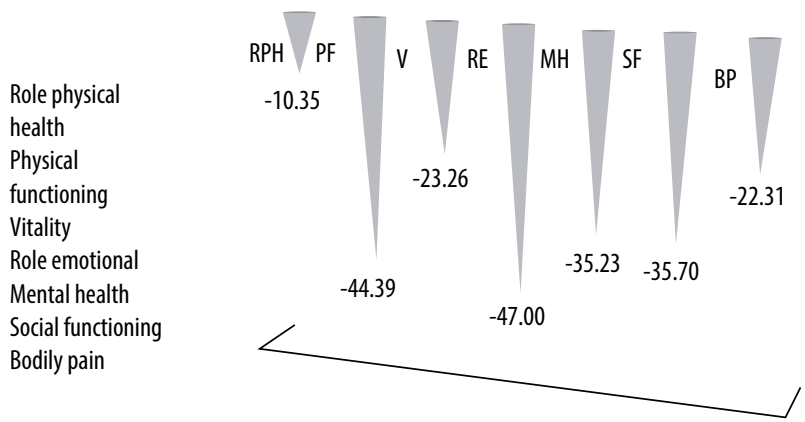

Figure 1. Relationship between the quality of life domains and the presence of PTSD.

Studies about the occurrence of PTSD in women suggest that this group is more vulnerable to the development of the disorder due to greater exposure to trauma involving violent events in childhood, adolescence and adulthood ${ }^{24}$. The presence of acute stress reactions after traumatic situations ${ }^{25}$ and a cognitive tendency to rumination ${ }^{26}$ amongst women are important factors that could help to explain the increased prevalence of PTSD in the female gender. The increased prevalence of current PTSD among individuals who live with a partner may be explained by the fact that the most common forms of violence against women are perpetrated by their own family members and intimate partners ${ }^{27}$. Several population-based studies from different countries demonstrated that $10 \%$ to $69 \%$ of the investigated women had suffered some lifetime form of physical violence by their partner, and $3 \%$ to $52 \%$ had experienced it in the previous year ${ }^{27}$.

The increased prevalence of PTSD amongst individuals from low socioeconomic classification may be understood through the relationship between low socioeconomic levels and worsened life conditions, such as: low schooling; lower access to health services; and low income ${ }^{28}$. Studies investigating risk factors for PTSD revealed that low educational levels and the presence of childhood adversities are more consistently associated with PTSD than gender, age and race ${ }^{29}$.
Different examinations have identified elevated comorbid rates in people with PTSD ${ }^{14,15}$. In the present study, the occurrence of comorbidities amongst individuals with current PTSD was really high; moreover, more than half of these subjects presented suicide risk. Anxiety symptoms in adolescents usually precede depressive symptoms ${ }^{30}$; in addition, the severity of posttraumatic symptoms is strongly associated with the presence of comorbidities ${ }^{16}$. Individuals with PTSD present a two or three times higher probability of presenting affective disorders, especially depression, when compared to individuals without the disorder ${ }^{28}$. Kessler et al. ${ }^{15}$ found that the chance of men with PTSD developing affective disorders is six to ten times higher than men without PTSD, whereas for women with PTSD this chance is four or five times higher than women without the disorder.

The analysis on the effects of PTSD as a risk factor for developing other psychiatric disorders allows the identification of such individuals as at risk for developing mood disorders or substance use-related disorders ${ }^{31}$. Evidence shows that once the symptoms of PTSD have remitted the increased risk for developing a secondary disorder disappears ${ }^{31}$. Kessler et al. ${ }^{15}$ found that PTSD usually precedes comorbid mood or substance use-related disorders. In women, PTSD often precedes conduct disorders. However, PTSD is not likely to precede other anxiety disorders ${ }^{15}$.

It is well-known that the elevated rates of comorbidities may make the PTSD diagnosis harder, since most common disorders are usually diagnosed first. In such cases, a detailed investigation about the patient's distress that could lead to a PTSD diagnosis may be delayed or even never made. This delay in properly investigating PTSD may contribute to the patient's continuous distress and to the chronicity of the disorder ${ }^{31}$.

The identification of PTSD in the general population allows proper referring for treatment and avoids the consequent aggravation of the disorder. It is well-known that PTSD is not commonly diagnosed at general outpatient services, especially due to the lack of knowledge by the primary care staff about the disorder ${ }^{4}$. Therefore, it is very important that the primary service professionals are able to identify any traumatic life events, since they are an alert for investigating PTSD.

The evaluation of quality of life of the young adults revealed significant impairments in all investigated levels, which refers to functional impairments in individuals with PTSD. Quality of life in individuals who have developed PTSD has been investigated ${ }^{5,32,33}$. Nonetheless, the sample of these studies is mostly originated from military populations and/ or victims of human or nature disasters. In this sense, there is a lack of literature regarding quality of life related to PTSD amongst civilian populations originated from locations without history of disasters. One recently-published Brazilian study sought to identify the impact of the severity of PTSD symptoms on quality of life of individuals who were victims 
of urban violence ${ }^{34}$. This study demonstrated that the greater the severity of PTSD symptoms the worst the quality of life. Even though the results point out in the same direction, the present study differs from the investigation of Pagotto et al. ${ }^{34}$ because of the use of a clinical sample with 65 people. On this regard, it is important to emphasize the relevance of the present investigation in revealing data originated from non-specific groups and in presenting a sample size that allows generalizations.

PTSD interferes with the individuals' and their families' lives in different ways, such as the avoidance behavior that may be developed in response to the constant presence of fear and similar feelings, and the appearance of interpersona $\left.\right|^{35}$ and marital problems ${ }^{36}$. Studies suggest that the occurrence of interpersonal difficulties after the traumatic event may be associated with the emotional numbness that follows such event ${ }^{37}$. An important issue about the effects of PTSD is the functional/work-related impairment. Regarding both absenteeism and lower productivity, this impairment is similar to what is observed in depressed individuals, even though it is smaller than the work-related impairments presented by people with panic disorder ${ }^{38}$.

In general, people tend to identify that something is wrong with their health when they notice changes regarding their ability to perform routine activities. Patients with PTSD often seek primary health units and medical outpatient clinics with somatic or general complaints 5 . An Australian population-based work reported that individuals with mental disorders presented impairments regarding the performance of routine activities that was approximately three times greater when compared to individuals without mental disorders $^{39}$. Also, an investigation on functional impairment in adults with current PTSD seeking basic health units in the city of New York (USA) demonstrated that individuals with current PTSD have a chance for presenting diminished quality of life that is four times higher than people that did not develop PTSD after a traumatic experience ${ }^{5,32}$.

\section{CONCLUSION}

The great advantage of this study was the evaluation of the occurrence of PTSD amongst young individuals from general population, who did not originate from general and mental health facilities. This is a population-based study in a medium-sized city without history of natural disasters and/or wars. The prevalence figures revealed in this city were high when compared to military population and victims of natural disasters. Investigations concerning PTSD in young individuals are important, since they enable the diagnosis of the disorder and the examination of the occurrence of previous traumatic events in the patient's life. The groups identified as at higher risk for the disorder are at need of a comprehen- sive investigation when they seek health services, since the probable damage caused by the delay in diagnosing and properly treating, in addition to the impairment in quality of life and the suffering caused by the presence of comorbidities characterizes the great amount of distress related to this disorder. This study is also relevant for increasing national database regarding PTSD since it remains little known at basic health units.

\section{Limitations}

The analyses comprised only association inferences between the outcome and the other variables, as the cross-sectional design did not allow causal inferences. Another limitation of this study is the fact that the instrument which was used to symptom screening (MINI) is not specific for the diagnosis of PTSD, does not evaluate symptom severity and does not question about the type of trauma experienced; this does not allow the description of the type of trauma experienced and possible correlations with the severity of symptoms. And finally, the small sample size limited the control for comorbidities in the regression analysis.

\section{INDIVIDUAL CONTRIBUTIONS}

Letícia Galery Medeiros - Analysis and interpretation of data, drafting the article and approval of the version to be published.

Luciano Dias de Mattos Souza - Conception and design of the study, drafting the article and approval of the version to be published.

Giovanna Del Grande da Silva - Conception and design of the study, critical review and approval of the version to be published.

Ricardo Tavares Pinheiro - Conception and design of the study, critical review and approval of the version to be published.

Ricardo Azevedo da Silva - Conception and design of the study, drafting the article and approval of the version to be published.

Karen Jansen - Design of the study, data interpretation, writing of article and approved the version to be published.

\section{ACKNOWLEDGEMENTS}

Dra. Medeiros is supported by a doctoral scholarship from Coordenação de Aperfeiçoamento de Pessoal de Nível Superior (Capes) and Fundação de Amparo à Pesquisa do Estado do Rio Grande do Sul (Fapergs), Brazil. This study was partly funded by the Conselho Nacional de Desenvolvimento Científico e Tecnológico (CNPq). 


\section{CONFLICTS OF INTEREST}

On behalf of all authors I assure that there are no conflicts of interest between authors and institution where the project was developed.

\section{REFERENCES}

1. Murthy RS. Mass violence and mental health: recent epidemiological findings. Int Rev Psychiatry. 2007;19(3):183-92.

2. Friedman M. Transtorno de estresse agudo e pós-traumático: as mais recentes estratégias de avaliação e tratamento. 4th ed. rev. Porto Alegre: Artmed; 2009.

3. Câmara Filho JW, Sougey EB. Transtorno de estresse pós-traumático: formulação diagnóstica e questões sobre comorbidade. Rev Bras Psiquiatr. 2001;23(4):221-8.

4. Figueira I, Mendlowicz M. Diagnóstico do transtorno de estresse pós-traumático. Rev Bras Psiquiatr. 2003;25(Suppl I):12-6.

5. Olatunji B0, Cisler JM, Tolin DF. Quality of life in the anxiety disorders: a meta-analytic review. Clin Psychology. 2007;27(5):572-81.

6. Giedd JN, Keshavan M, Paus T. Why do many psychiatric disorders emerge during adolescence? Nat Rev Neurosci. 2008;9(12):947-57.

7. Merikangas KR. Vulnerability factors for anxiety disorders in children and adolescents. Child Adolesc Psychiatric Clin N Am. 2005;14(4):649-79.

8. Instituto Brasileiro de Geografia e Estatística (IBGE). Avaiable from: <http://www.ibge. gov.br>. Accessed on: May 15, 2008.

9. Jansen K, Ores LC, Cardoso TA, Lima RC, Souza LD, Magalhães PV, et al. Prevalence of episodes of mania and hypomania and associated comorbidities among young adults. J Affect Disord. 2011;130(1-2):328-33.

10. Associação Brasileira de Estudos Populacionais (Abep). Data based on the socio economic survey (Ibope). Avaiable from: <http://www.abep.org.br>. Accessed on: May 15, 2008.

11. Henrique IFS, Micheli D, Lacerda RB, Lacerda LA, Formigoni MLOS. Validação da versão brasileira do teste de triagem do envolvimento com álcool, cigarro e outras substâncias (ASSIST). Rev Assoc Med Bras. 2004;50(2):199-206.

12. Ciconelli RM, Ferraz MB, Santos W, Meinão I. Tradução para a língua portuguesa e validação do questionário genérico de avaliação de qualidade de vida SF-36 (Brasil SF-36). Rev Bras Reumatol. 1999;39(3):143-50.

13. Amorim P. Mini International Neuropsychiatric Interview (MINI): validação de entrevista breve para diagnóstico de transtornos mentais. Rev Bras Psiquiatr. 2000;22(3):106-15.

14. Leray E, Camara A, Drapier D, Riou F, Bougeant N, Pelissolo A, et al. Prevalence, characteristics and comorbidities of anxiety disorders in France: results from the "Mental Health in General Population" Survey (MHGP). Eur Psychiatry. 2011;26(6):339-45.

15. Kessler RC, Sonnega A, Bromet E, Hughees M, Nelson CB. Posttraumatic stress disorder in the National Comorbidity Survey. Arch Gen Psychiatry. 1995;52(12):1048-60.

16. Kessler RC, Chiu WT, Demler O, Merikangas KR, Walters EE. Prevalence, severity, and comorbidity of 12-month DSM-IV disorders in the National Comorbidity Survey Replication. Arch Gen Psychiatry. 2005;62(6):617-27.

17. Bremner JD, Southwick SM, Johnson DR, Yehuda R, Charney DS. Childhood physical abuse and combat-related posttraumatic stress disorder in Vietnam veterans. Am J Psychiatry. 1993;150(2):235-9.

18. Nishith P, Mechanic MB, Resick PA. Prior interpersonal trauma: the contribution to current PTSD symptoms in female rape victims. J Abnorm Psychol. 2000;109(1):20-5.
19. Martine H, Francine L, Martin B. Post Traumatic Stress Disorder/PTSD in adolescent victims of sexual abuse: resilience and social support as protection factors. Cien Saude Colet. 2014;19(3):685-94.

20. Havens JF, Gudiño OG, Biggs EA, Diamond UN, Weis JR, Cloitre M. Identification of trauma exposure and PTSD in adolescent psychiatric inpatients: an exploratory study. J Trauma Stress. 2012;25(2):171-8.

21. Razzouk D, Zorzetto R, Dubugras MT, Gerolin J, Mari JJ. Mental health and psychiatry research in Brazil: scientific production from 1999 to 2003. Rev Saúde Pública. 2006;40:93-100.

22. Andreoli SB, Almeida Filho N, Coutinho ESF, Mari JJ. Identificação de casos psiquiátricos em estudos epidemiológicos multifásicos: métodos, problemas e aplicabilidade. Rev Saúde Pública. 2000;34(5):475-83.

23. Andrade LH, Wang YP, Andreoni S, Silveira CM, Silva CA, Siul ER, et al. Mental disorders in megacities: findings from the São Paulo megacity mental health survey, Brazil. PLOS One. 2012;7(2):e31879.

24. Spinhoven P, Penninx BW, van Hemert AM, de Rooij M, Elzinga BM. Comorbidity of PTSD in anxiety and depressive disorders: prevalence and shared risk factors. Child Abuse Negl. 2014;38(8):1320-30.

25. Dyb G, Jensen TK, Nygaard E, Ekeberg 0, Diseth TH, Wentzel-Larsen T, et al. Post-traumatic stress reactions in survivors of the 2011 massacre on Utøya Island, Norway. Br J Psychiatry. 2014;204:361-7.

26. Moore SA, Zoellner LA, Mollenholt N. Are expressive suppression and cognitive reappraisal associated with stress-related symptoms? Behav Res Ther. 2008;46(9):993-1000.

27. Andrade LHSG, Viana MC, Silveira CM. Epidemiologia dos transtornos psiquiátricos na muIher. Rev Psiq Clin. 2006;33:43-54.

28. Jacobi F, Wittchen HU, Holting C, Hofler M, Pfister H, Muller N, et al. Prevalence, co-morbidity and correlates of mental disorders in the general population: results from the German Health Interview and Examination Survey (GHS). Psychol Med. 2004;34(4):597-611.

29. Brewin $(R$, Andrews $B$, Valentine JD. Meta-analysis of risk factors for posttraumatic stress disorder in trauma-exposed adults. J Consult Clin Psychol. 2000;68(5):748-66.

30. Reinherz HZ, Paradis AD, Giaconia RM, Stashwick CK, Fitzmaurice G. Childhood and adolescent predictors of major depression in the transition to adulthood. Am J Psychiatry. 2003;160(12):2141-7.

31. Margis R. Comorbidade no transtorno de estresse pós-traumático: regra ou exceção? Rev Bras Psiquiatr. 2003;25(Supl I):17-20.

32. Westphal M, Olfson M, Gameroff MJ, Wickramaratne P, Pilowsky DJ, Neugebauer R, et al. Functional impairment in adults with past posttraumatic stress disorder: findings from primary care. Depress Anxiety. 2011;28(8):686-95.

33. Mendlowicz MV, Stein MB. Quality of life in individuals with anxiety disorders. Am J Psychiatry. 2000;157(5):669-82.

34. Pagotto LF, Mendlowicz MV, Coutinho ESF, Figueira I, Luza MP, Araujo AX, et al. The impact of posttraumatic symptoms and comorbid mental disorders on the health-related quality of life in treatment-seeking PTSD patients. Compr Psychiatry. 2015;58:68-73.

35. Taft CT, Watkins LE, Stafford J, Street AE, Monson CM. Posttraumatic stress disorder and intimate relationship problems: a meta-analysis. J Consult Clin Psych. 2011;79(1):22-33.

36. Lambert JE, Engh R, Hasbun A, Holzer J. Impact of posttraumatic stress disorder on the relationship quality and psychological distress of intimate partners: a meta-analytic review. J Fam Psychol. 2012;26(5):729-37.

37. Monson CM, Taft CT, Fredman SJ. Military-related PTSD and intimate relationships: from description to theory-driven research and intervention development. Clin Psychol Rev. 2009;29(8):707-14

38. Bravo-Mehmedbašić A, Kučukalić A, Kulenović AD, Suljić E. Impact of chronic posttraumatic stress disorder on the quality of life of war survivors. Psychiat Danub. 2010;22(3):430-5.

39. Henderson $S$, Andrews $G$, Hall W. Australia's mental health: an overview of the general population survey. Aust N Z J Psychiatry. 2000;34(2):197-205. 